\title{
Deterministic and probabilistic 3D analysis of slope rupture at BR 116 PR/SP highway in unsaturated soil
}

\author{
Bianca Riselo ${ }^{1 *}$, Larissa Passini², and Alessander Kormann ${ }^{2}$ \\ ${ }^{1}$ MSc. Student, Graduate Program in Civil Construction Engineering, Federal University of Paraná, Curitiba 81531, Brazil \\ ${ }^{2}$ Professor, Graduate Program in Civil Construction Engineering, Federal University of Paraná, Curitiba 81531, Brazil
}

\begin{abstract}
This research was developed with the purpose of presenting a deterministic and probabilistic assessment of the stability of slope located in state of São Paulo-Brazil, in the area denominated Serra Pelada, BR 116 PR/SP, with the incorporation of different suction scenarios in the unsaturated soil. The methodology was composed by 2D and 3D modelling of the slope, in the SoilVision's SVSlope software, with the imposition of two water levels on the slope, one of 6.5 meters deep and another of 7.5 meters. The results demonstrate the variability of the probability of rupture, the safety factor, and the quantification of mobilized mass volume, in the six suction scenarios. As a result, it is possible to conclude with the analysis that the greater the surface suction in the unsaturated soil, the greater the safety factors of the slope and the lower the probability of rupture. It is also prudent to add that the incorporation of the variability of the geotechnical parameters in the probability analysis of stability, together with the 3D modelling of the slope, allow a more reliable analysis, presenting results of greater applicability in subsequent analyses. Finally, in conclusion, the studied slope is safe regarding its global stability for rupture.
\end{abstract}

\section{Introduction}

Landslides can cause great impact regionally, causing changes in the environment, possible injuries and fatalities in the population, in addition to economic losses, such as highway maintenance costs in the case of road embankments. Thus, analyse the stability of the slopes is of paramount importance because it guarantees greater security for the slope itself as well as for the population and region, and it is also possible to predict its performance in front of the imposed scenarios.

The slope stability analysis aims to evaluate the possibility of a landslide occurring (Gerscovich 2016 [1]). There are two types of analysis: deterministic and probabilistic. The first analysis uses in its calculations the average values of the soil resistance parameters, such as cohesion intercept and friction angle, and calculates only one safety factor for the situation. The probabilistic stability analysis considers the variation of soil parameters and can quantify the uncertainties inherent to the deterministic safety factor through the determination of the probability of rupture and the slope reliability index, assisting in the decision making of the geotechnical engineer in situations where slopes have a low safety factor but do not have an imminent risk of landslides (Tonus 2009 [2]). Furthermore, through the search for the critical failure surface on the slope, it is possible to estimate the volume of mass to be mobilized with the sliding, in addition to the visualization of this volume because the modelling is done in 3D.
In this study it is important to know the concept of unsaturated soils. According to Marinho et al. (1994) [3] refers to the soil with a multiphase system, that is, it is composed of a solid phase, liquid and gas. In Brazil there are many soils in unsaturated condition. The concept of suction is also relevant, which according to Victorino (2015) [4] is the force of water absorption by a porous element. The suction loss is considered one of the slope instability mechanisms due to the increase in soil moisture, as a result of the advance of water infiltration, which may cause the rupture of the massif without the condition of soil saturation being reached (Fredlund 1987, apud Fernandes et al. 2001 [5]).

Thus, the aim of this study was to present a deterministic and probabilistic assessment of the stability of slope located in the state of São Paulo, in Brazil, in the area denominated Serra Pelada of BR 116 PR / SP, with the incorporation of different suction scenarios in the unsaturated soil layer.

\section{Materials and methods}

This section of the article presents the materials and methods used, divided into a description of the study area, input parameters and numerical modelling.

\subsection{Description of the study area}

The studied slope is located in the state of São Paulo in Brazil, in the area denominated Serra Pelada, which

\footnotetext{
* Corresponding author: bihdetoni@hotmail.com
} 
belongs to the chain of mountains of Serra do Mar, on the BR-116 Régis Bittencourt highway, specifically at $\mathrm{km} 551+600$ - south lane (Fig. 1). The slope has a height of 17 meters, a front length of 37 and an average slope of $34^{\circ}$. Fig. 2 shows the frontal view of the embankment that contemplates its beginning and end, respectively. The selection of this location was based on the study by Batista (2019) [6]. The author identified the present region as the one with the greatest economic risk, being considered the most critical in risk analyses.
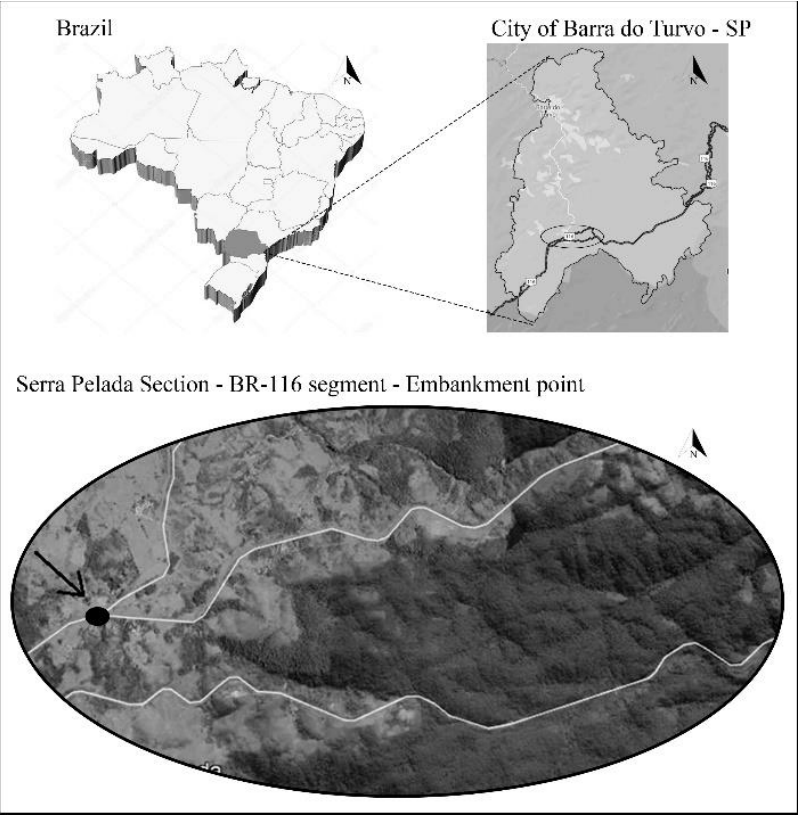

Fig. 1. Study area location

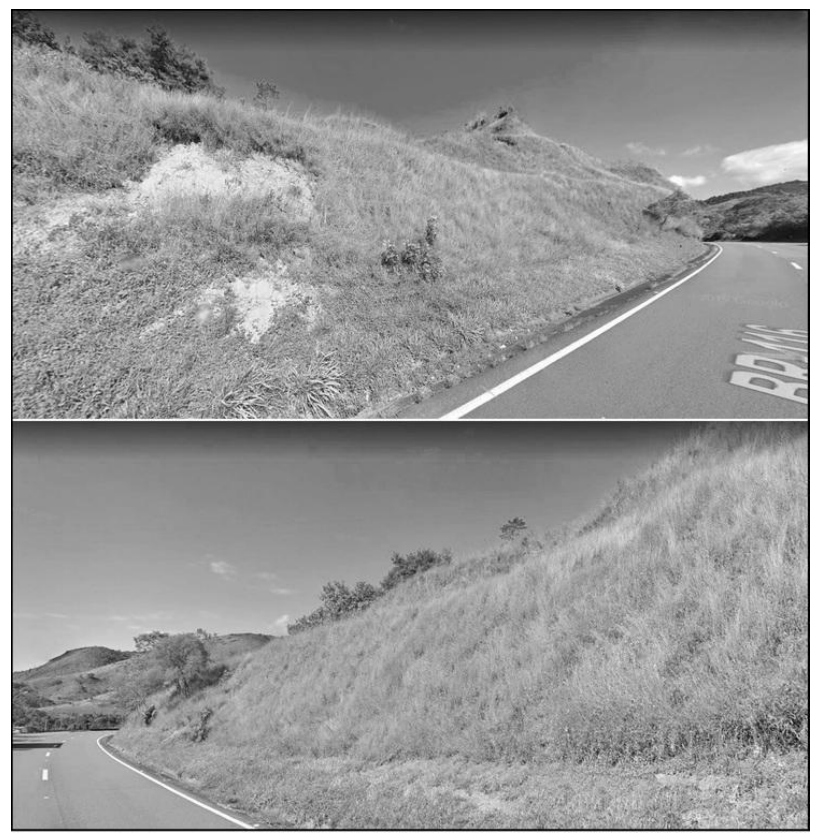

Fig. 2. Front views of the slope study.

The slope presents geological formation characterized by amphibolite gneiss, according to the geological map. The stratigraphic profile of the embankment was shaped through geotechnical investigations of the SPT type (Standard Penetration Test), carried out in an area close to the study ( $\mathrm{km} 552+$ 200 - south lane), consisting of three soil layers: (i) 1.5 meters of colluvium (top layer), (ii) 4.5 meters of residual soil formed by sandy silt (middle layer) and (iii) bellow that, a parent rock layer (saprolite).

The water level was considered at two different depths, 6.5 meters from the surface and 7.5 meters. The depth of 7.5 meters was obtained from data from geotechnical investigations and the depth of 6.5 meters was chosen to analyse the interference of the position of the water level in the results of safety factor, probability of rupture and volume of mass mobilized.

\subsection{Input parameters}

The input parameters are the soil shear strength parameters, such as the friction angle and cohesion intercept, natural specific weight of the soil, suction and the water retention characteristic curves.

The shear strength parameters of the colluvial, residual soils and saprolite, were estimated based on data from Trevizolli (2018) [7]. The author carried out direct shear tests on saturated soil, of the controlled deformation type, in three non-deformable blocks, in three normal stress levels, $50 \mathrm{kPa}, 100 \mathrm{kPa}$ and $200 \mathrm{kPa}$, on the slope located near the site, at $\mathrm{km} 552+000$, north lane. The Table 1 presents the ranges of values and the average value used for the parameters of natural specific weight of the soil ( $\gamma$ nat), friction angle $(\Phi)$ and cohesion intercept ( $\left.\mathrm{c}^{\prime}\right)$, of the two soils in the probabilistic stability analysis. It is noteworthy that the average value of soil parameters colluvial is not the direct average of the values, because of the three non-deformable blocks two were of colluvial soil, thus the average is the average value between the average of the minimum value of the two blocks and the average of the maximum value of the two blocks.

Table 1. Resistance parameters and natural specific weight for colluvial and residual soils.

\begin{tabular}{c|c|c|c|c|c|c}
\hline Material & \multicolumn{3}{|c|}{ Colluvial soil } & \multicolumn{3}{c}{ Residual soil } \\
\hline Parameter & $\begin{array}{c}\gamma \text { nat } \\
\left(\mathrm{kN} / \mathrm{m}^{3}\right)\end{array}$ & $\begin{array}{c}\Phi \\
\left({ }^{\circ}\right)\end{array}$ & $\begin{array}{c}\mathrm{c}^{\prime} \\
(\mathrm{kPa})\end{array}$ & $\begin{array}{c}\gamma \text { nat } \\
\left(\mathrm{kN} / \mathrm{m}^{3}\right)\end{array}$ & $\begin{array}{c}\Phi \\
\left({ }^{\circ}\right)\end{array}$ & $\begin{array}{c}\mathrm{c}^{\prime} \\
(\mathrm{kPa})\end{array}$ \\
\hline $\begin{array}{c}\text { Average } \\
\text { value }\end{array}$ & 16.0 & 23.5 & 11.4 & 18.00 & 26.0 & 7.8 \\
$\begin{array}{c}\text { Minimum } \\
\text { value }\end{array}$ & - & 17.8 & 4.7 & - & 21.8 & 5.1 \\
$\begin{array}{c}\text { Maximum } \\
\text { value }\end{array}$ & - & 30.0 & 16.8 & - & 30.2 & 10.4 \\
$\begin{array}{c}\text { Standard } \\
\text { deviation }\end{array}$ & - & 6.5 & 6.7 & - & 4.2 & 2.7 \\
$\begin{array}{c}\text { Coefficient } \\
\text { of variation }\end{array}$ & - & 27.5 & 58.7 & - & 16.2 & 34.2 \\
\hline
\end{tabular}

The maximum value of the parameters was defined based on the value of the peak resistance parameters, while the minimum value was based on the value of the residual resistance parameters. 
In statical analysis, the coefficient of variation is interpreted as the variability of the data in relation to the mean. Lower values of coefficient of variation indicate a more homogeneous data set. Table 1 shows a large dispersion in the coefficients of variation, with values ranging from $16.2 \%$ to $58.7 \%$. For the cohesion intercept parameter, the coefficients of variation are even higher. This characteristic can be linked to the influence of some factors, such as stress history, voids index, cementations, among others.

For saprolite, the third layer of soil, only the average value of the parameters was considered, $18 \mathrm{kN} / \mathrm{m}^{3}$ for the natural specific weight, $39^{\circ}$ for the friction angle and $10.4 \mathrm{kPa}$ for the cohesion intercept.

Suction was incorporated into the first three meters of surface layer, of which three were 1.5 meters of colluvial soil followed by 1.5 meters of residual soil. The depth of 3 meters was considered a $0 \mathrm{kPa}$ suction and the surface the total suction value, that is, from the surface layer to 3 meters in depth the value of the total suction decreases linearly. Therefore, the range of 20 to $120 \mathrm{kPa}$ for total suction at the soil surface was adopted, based on the study and analysis by Trevizolli (2018) [7].

These first three meters of depth, composed of colluvial and residual soil, were defined as unsaturated soils. Each soil has its water retention characteristic curves, which were defined based on the set of experimental points obtained by Trevizolli (2018) [7], through the filter paper test methodology, standardized by ASTM D 5298 - 03, and subsequently adjusted. The colluvial soil presented a water retention characteristic curve with a bi-modal shape and the residual soil a curve with a tri-modal shape. The adjusted curves were inserted into the software through the set of points for each one. The residual moisture contents were extracted from the curves, the residual soil presented $20 \%$ and the colluvial soil $30 \%$ residual moisture content.

\subsection{Numerical modelling}

The simulations of deterministic and probabilistic stability analysis were performed using SoilVision's SVSlope software. The probabilistic methodology used was Monte Carlo with 5000 realisations. The Morgenstern-Price limit equilibrium method was chosen to determine the safety factor in each simulation, because it is considered a rigorous method and includes the balance of forces and moments in each analysed slice.

In the modelling, it was adopted for the unsaturated soils (colluvial soil and the first 1.5 meters of the residual soil), their respective water retention characteristic curves. For the other soils (last 3.0 meters of residual soil and saprolite), the Mohr-Coulomb method was chosen to categorize the materials.

The total suction on the slope surface was considered to range from 20 to $120 \mathrm{kPa}$, varying in each simulation from $20 \mathrm{kPa}$ to $20 \mathrm{kPa}$. These suction levels were inserted considering the maximum value analysed at the surface and at the end of the 3.0 surface meters, which are the depth of the unsaturated soil, such as $0 \mathrm{kPa}$, that is, the suction value was decreasing linearly within the unsaturated soil.

The slope was modelled in $2 \mathrm{D}$ visualization, which would be the cross section (Fig. 3), and in 3D visualization (Fig. 4). The inclined part of the slope was simplified due to its large number of points, so it was considered a continuous inclination, however the top and bottom of the slope were maintained.

\section{Results and discussions}

The results obtained from the stability analyses were the safety factor (SF) of the simulation, the probability of rupture of the slope, which is the probability of the occurrence of a safety factor equal to or less than 1.0, for

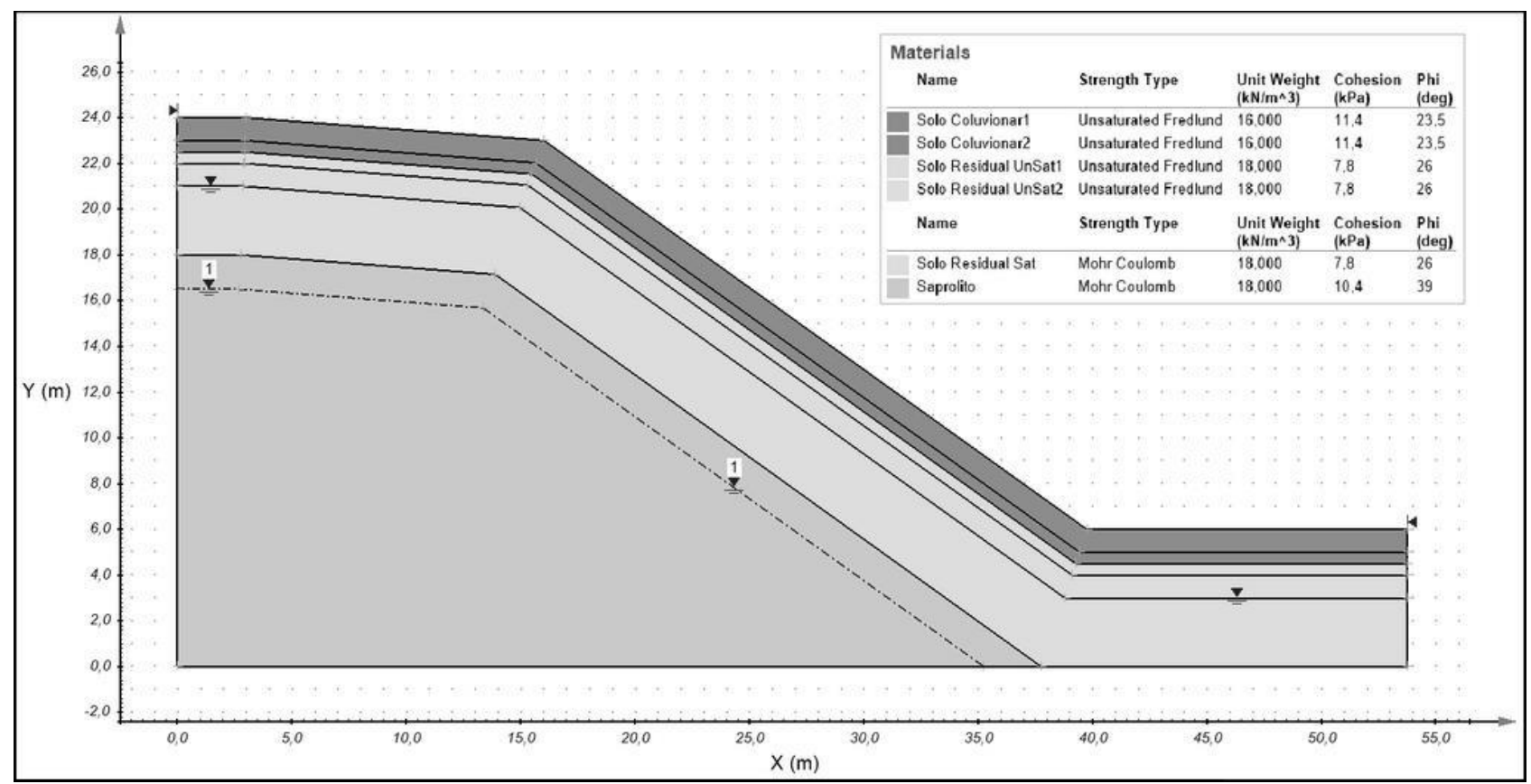

Fig. 3. Type cross section. 


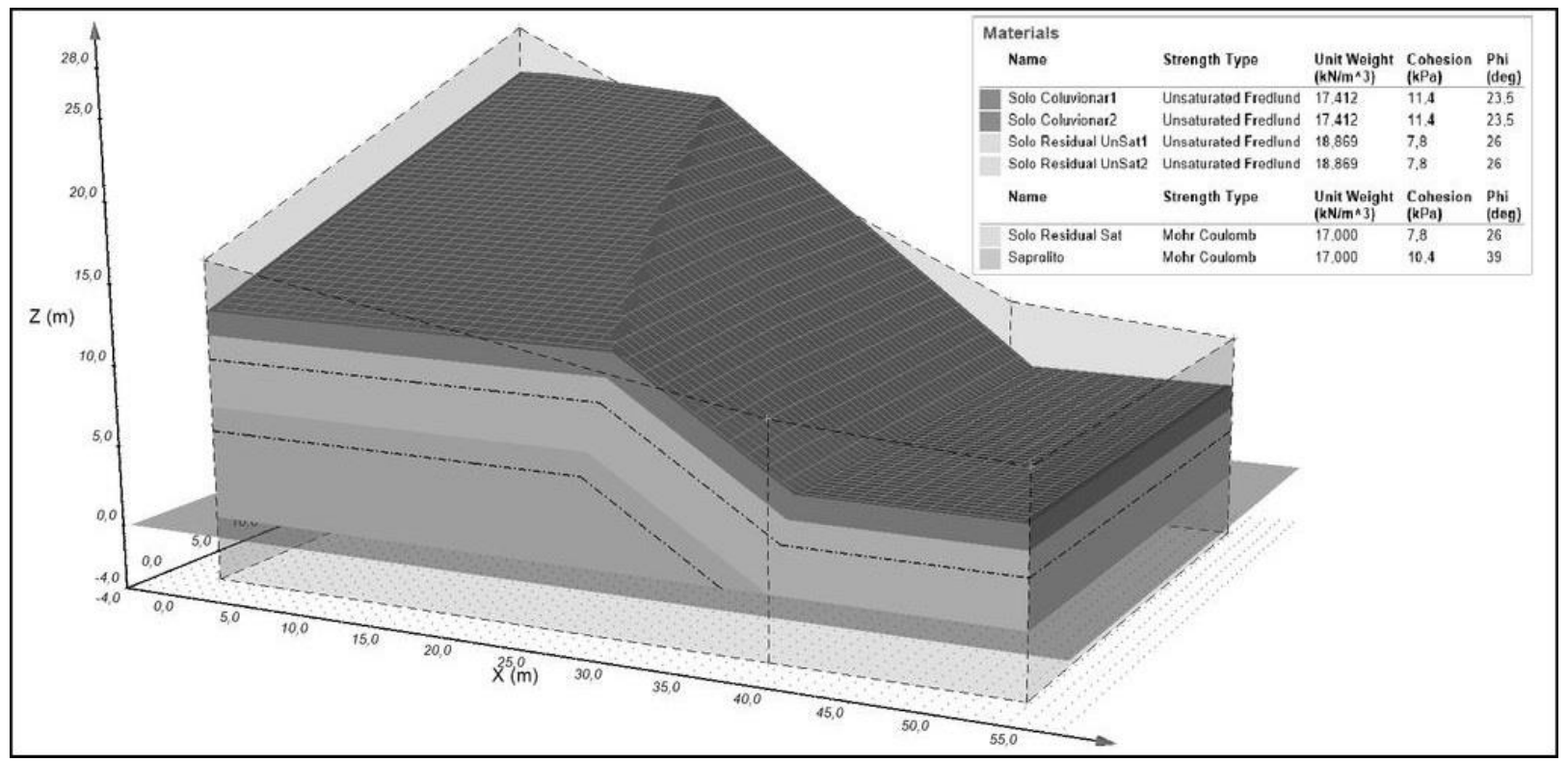

Fig. 4. 3D slope modelling.

Table 2. Summary table of the results obtained in the water level position at 6.5 meters.

\begin{tabular}{|c|c|c|c|c|c|c|c|c|}
\hline \multirow{2}{*}{$\frac{8}{3}$} & \multirow{2}{*}{$\begin{array}{c}\text { Suction } \\
(\mathrm{kPa})\end{array}$} & \multirow{2}{*}{$\begin{array}{l}\text { Prob. } \\
\text { of } \\
\text { rupture } \\
(\%)\end{array}$} & \multicolumn{2}{|c|}{$\mathrm{SF}$} & \multicolumn{2}{|c|}{$\begin{array}{l}\text { Volume } \\
\left(\mathrm{m}^{3} / \mathrm{m}\right)\end{array}$} & \multicolumn{2}{|c|}{$\begin{array}{l}\text { Volume } \\
\left(\mathrm{m}^{3}\right)\end{array}$} \\
\hline & & & Det & Prob & Det & Prob & Det & Prob \\
\hline \multirow{6}{*}{$\begin{array}{l}2 \\
\mathrm{D}\end{array}$} & 20 & 0.28 & & 248 & \multirow{6}{*}{\multicolumn{2}{|c|}{159.90}} & \multirow{6}{*}{\multicolumn{2}{|c|}{5916.30}} \\
\hline & 40 & 0.04 & & 293 & & & & \\
\hline & 60 & 0.02 & \multirow{2}{*}{\multicolumn{2}{|c|}{1.355}} & & & & \\
\hline & 80 & \multirow{3}{*}{0.00} & & & & & & \\
\hline & 100 & & \multicolumn{2}{|c|}{1.377} & & & & \\
\hline & 120 & & \multicolumn{2}{|c|}{1.388} & & & & \\
\hline \multirow{6}{*}{$\begin{array}{l}3 \\
\mathrm{D}\end{array}$} & 20 & \multirow{6}{*}{0.00} & \multicolumn{2}{|c|}{1.438} & \multicolumn{2}{|c|}{40.89} & \multicolumn{2}{|c|}{1513.00} \\
\hline & 40 & & \multicolumn{2}{|c|}{1.457} & \multicolumn{2}{|c|}{35.30} & \multicolumn{2}{|c|}{1306.00} \\
\hline & 60 & & \multicolumn{2}{|c|}{1.518} & \multicolumn{2}{|c|}{31.81} & \multicolumn{2}{|c|}{1177.00} \\
\hline & 80 & & \multicolumn{2}{|c|}{1.675} & \multicolumn{2}{|c|}{49.59} & \multicolumn{2}{|c|}{1835.00} \\
\hline & 100 & & \multicolumn{2}{|c|}{1.773} & \multicolumn{2}{|c|}{41.78} & \multicolumn{2}{|c|}{1546.00} \\
\hline & 120 & & \multicolumn{2}{|c|}{1.850} & \multicolumn{2}{|c|}{58.05} & \multicolumn{2}{|c|}{2148.00} \\
\hline
\end{tabular}

a specific level of suction on the soil surface, and the volumes of soil mass mobilized by the rupture of the slope, all of them for the two situations of water level position, at 6.5 meters and 7.5 meters deep.

Table 2 shows the summary of the results obtained for the critical rupture surface with a water level of 6.5 meters. Table 3 shows these same results for the position of the water level at 7.5 meters.

The rupture probability reached its highest value, $0.28 \%$, in the $20 \mathrm{kPa}$ surface suction scenario, for 2D analyses. According to the USACE classification (1999) [8] this rupture probability value indicates an expected level of performance above the average. The other
Table 3. Summary table of the results obtained in the water level position at 7.5 meters.

\begin{tabular}{|c|c|c|c|c|c|c|c|c|}
\hline \multirow{2}{*}{$\frac{0}{\frac{0}{2}}$} & \multirow{2}{*}{$\begin{array}{c}\text { Suction } \\
(\mathrm{kPa})\end{array}$} & \multirow{2}{*}{$\begin{array}{c}\text { Prob. } \\
\text { of } \\
\text { rupture } \\
(\%)\end{array}$} & \multicolumn{2}{|c|}{ SF } & \multicolumn{2}{|c|}{$\begin{array}{l}\text { Volume } \\
\left(\mathrm{m}^{3} / \mathrm{m}\right)\end{array}$} & \multicolumn{2}{|c|}{$\begin{array}{c}\text { Volume } \\
\left(\mathrm{m}^{3}\right)\end{array}$} \\
\hline & & & Det & Prob & Det & Prob & Det & Prob \\
\hline \multirow{6}{*}{$\begin{array}{l}2 \\
\mathrm{D}\end{array}$} & 20 & 0.28 & & 248 & \multirow{6}{*}{\multicolumn{2}{|c|}{159.90}} & \multirow{6}{*}{\multicolumn{2}{|c|}{5916.30}} \\
\hline & 40 & 0.04 & & 293 & & & & \\
\hline & 60 & 0.02 & \multirow{2}{*}{\multicolumn{2}{|c|}{$\begin{array}{l}1.321 \\
1.355\end{array}$}} & & & & \\
\hline & 80 & \multirow{3}{*}{0.00} & & & & & & \\
\hline & 100 & & \multicolumn{2}{|c|}{1.377} & & & & \\
\hline & 120 & & \multicolumn{2}{|c|}{1.388} & & & & \\
\hline \multirow{6}{*}{$\begin{array}{l}3 \\
\mathrm{D}\end{array}$} & 20 & \multirow{6}{*}{0.00} & \multicolumn{2}{|c|}{1.361} & \multicolumn{2}{|c|}{36.57} & \multicolumn{2}{|c|}{1353.00} \\
\hline & 40 & & \multicolumn{2}{|c|}{1.531} & \multicolumn{2}{|c|}{47.05} & \multicolumn{2}{|c|}{1741.00} \\
\hline & 60 & & \multicolumn{2}{|c|}{1.541} & \multicolumn{2}{|c|}{42.30} & \multicolumn{2}{|c|}{1565.00} \\
\hline & 80 & & \multicolumn{2}{|c|}{1.614} & \multicolumn{2}{|c|}{23.43} & \multicolumn{2}{|c|}{867.00} \\
\hline & 100 & & \multicolumn{2}{|c|}{1.652} & \multicolumn{2}{|c|}{48.05} & \multicolumn{2}{|c|}{1778.00} \\
\hline & 120 & & \multicolumn{2}{|c|}{1.714} & \multicolumn{2}{|c|}{51.38} & \multicolumn{2}{|c|}{1901.00} \\
\hline
\end{tabular}

values achieved in the other suction scenarios, of the $2 \mathrm{D}$ visualization $(0.04 \% ; 0.02 \%$ and $0 \%)$ and those obtained in the $3 \mathrm{D}$ visualization $(0 \%)$ indicate a good and high expected performance level.

The USACE classification (1999) [8] indicates that a failure probability greater than $10 \%$ compromises the instability of the slope, transforming the expected performance level into risk. On the other hand, a probability of failure below $0.1 \%$ indicates an expected level of performance above average, with low susceptibility to the occurrence of landslides. Therefore, the slope is stable due to the low probability of landslide. 


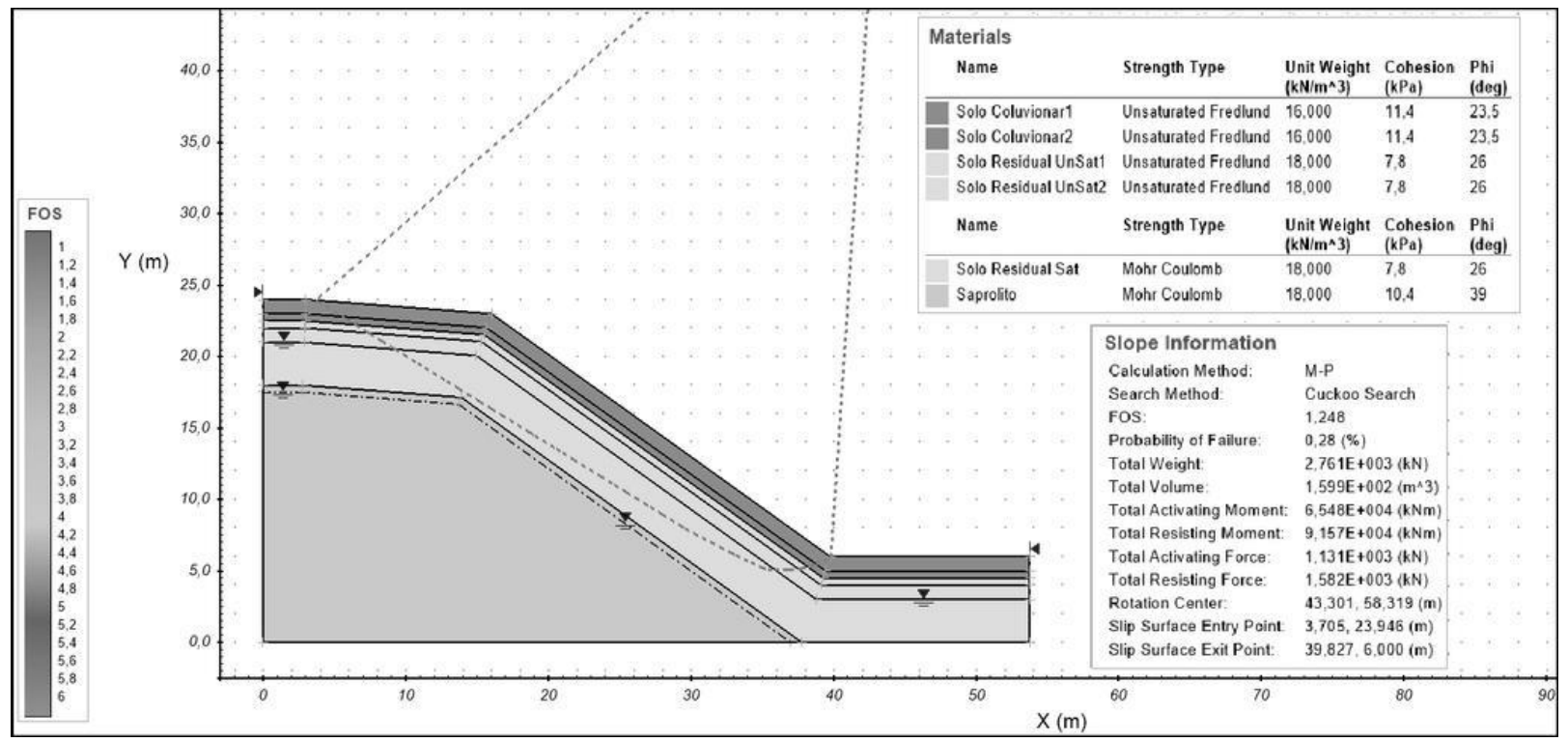

Fig. 5. 2D probabilistic analysis in SVSlope with water level at 6.5 meters.

The Brazilian standard NBR 11682 (ABNT 2009 [9]) establishes values of minimum safety factors (SF) for landslides, due to the loss of human life and material and environmental damage. Therefore, for the region under analysis, considering the level of safety against damage to human lives as medium and the level of safety against material and environmental damage as low, the minimum safety factor for landslide the slope study would be 1.3 .

The safety factors of the $20 \mathrm{kPa}$ and $40 \mathrm{kPa}$ surface suction scenarios in the 2D analysis, among all the safety factors values obtained in the results, of both water levels, indicated the slope as unsafe, that is, values less than 1.3. In the other $2 \mathrm{D}$ scenarios and in all 3D scenarios the slope is safe, with no possibility of landslide.
In addition, the increase in surface suction resulted in an increase in the SF, thus ensuring greater safety to the slope. The lowest safety factor (1.248) indicated the slope as unsafe. However, the probability of rupture designated an expected level of performance above the average, that is, no matter how low the safety factor (SF) is, this does not always indicate that the slope will break, as is the case of this slope, which was considered stable in all simulated scenarios.

The volume of mobilized mass quantified in 2D analysis was the same for all scenarios of surface suction because the critical rupture surface is the same for all these scenarios. In 3D analysis, because it is in three dimensions, the volume changed from one scenario to another. In each scenario, the critical break surface was different because it was analysed over the entire length of the slope and not just in a specific cross section.

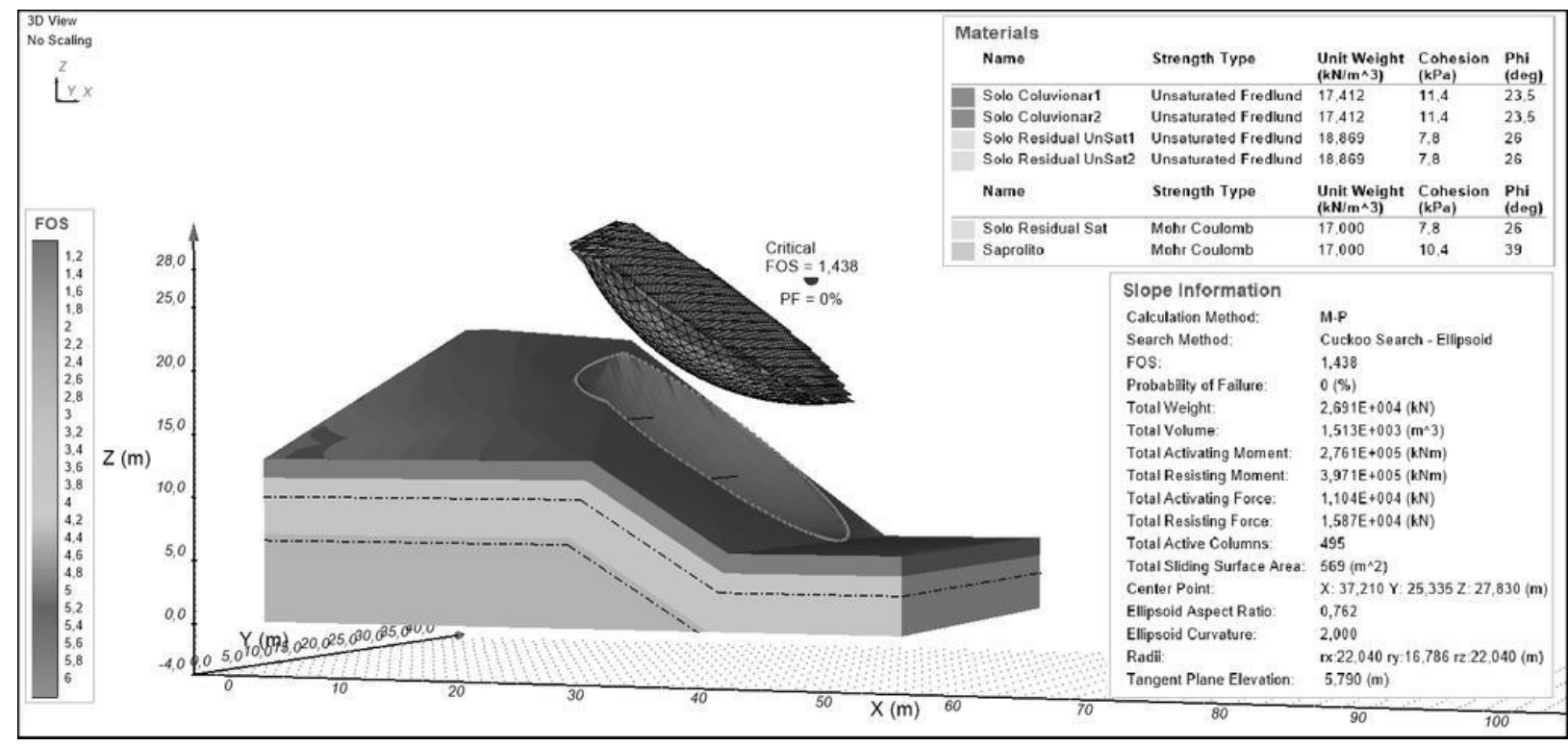

Fig. 6. 3D probabilistic analysis in SVSlope with water level at 6.5 meters. 


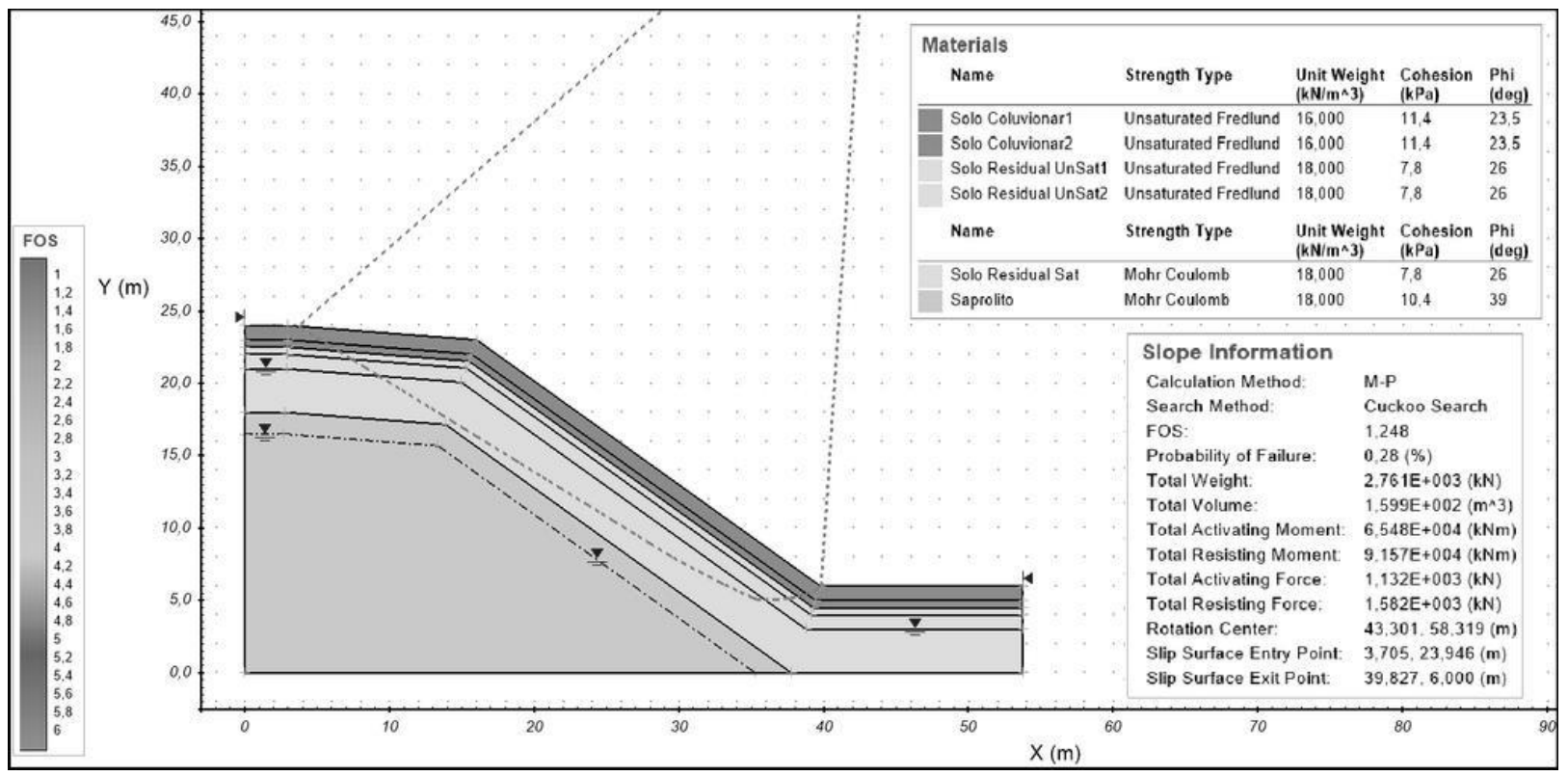

Fig. 7. 2D probabilistic analysis in SVSlope with water level at 7.5 meters.

In this way, there were situations where the surface was located at the highest end of the slope, as well as situations that were located in the middle of it, resulting different values of mobilized mass volume because there are rupture surfaces with different shapes and specifications, with a total value of $5916.30 \mathrm{~m}^{3}$ in $2 \mathrm{D}$ analysis and ranging between $867 \mathrm{~m}^{3}$ and $2148 \mathrm{~m}^{3}$ in 3D analysis. It is worth noting that with the increase in surface suction there was not necessarily an increase in volume, as is observed in the suction scenario of $60 \mathrm{kPa}$ of water level at $6.5 \mathrm{~m}$ from the 3D analysis, as well as in the suction scenario of $80 \mathrm{kPa}$ of water level $7.5 \mathrm{~m}$ from the 3D analysis, cannot be established no connection.

Fig. 5 and Fig. 6 shows one of the probabilistic analyses made in the SVSlope software and the results obtained in $2 \mathrm{D}$ and $3 \mathrm{D}$ visualization, respectively, in this case, for the water level depth at 6.5 meters and $20 \mathrm{kPa}$ surface suction. Fig. 7 and Fig. 8 show one of the probabilistic analyses made in the SVSlope software and the results obtained in $2 \mathrm{D}$ and $3 \mathrm{D}$ visualization, respectively, in this case, for the water level depth at 7.5 meters and $20 \mathrm{kPa}$ surface suction.

Regarding the results obtained with $2 \mathrm{D}$ and $3 \mathrm{D}$ visualizations, there is a difference between them. The probability of rupture indicated a safer scenario (lower values) in the $3 \mathrm{D}$ analysis, because in this analysis it was possible to consider all the possibilities of landslides in the three dimensions, unlike the 2D analysis which was limited to two dimensions.

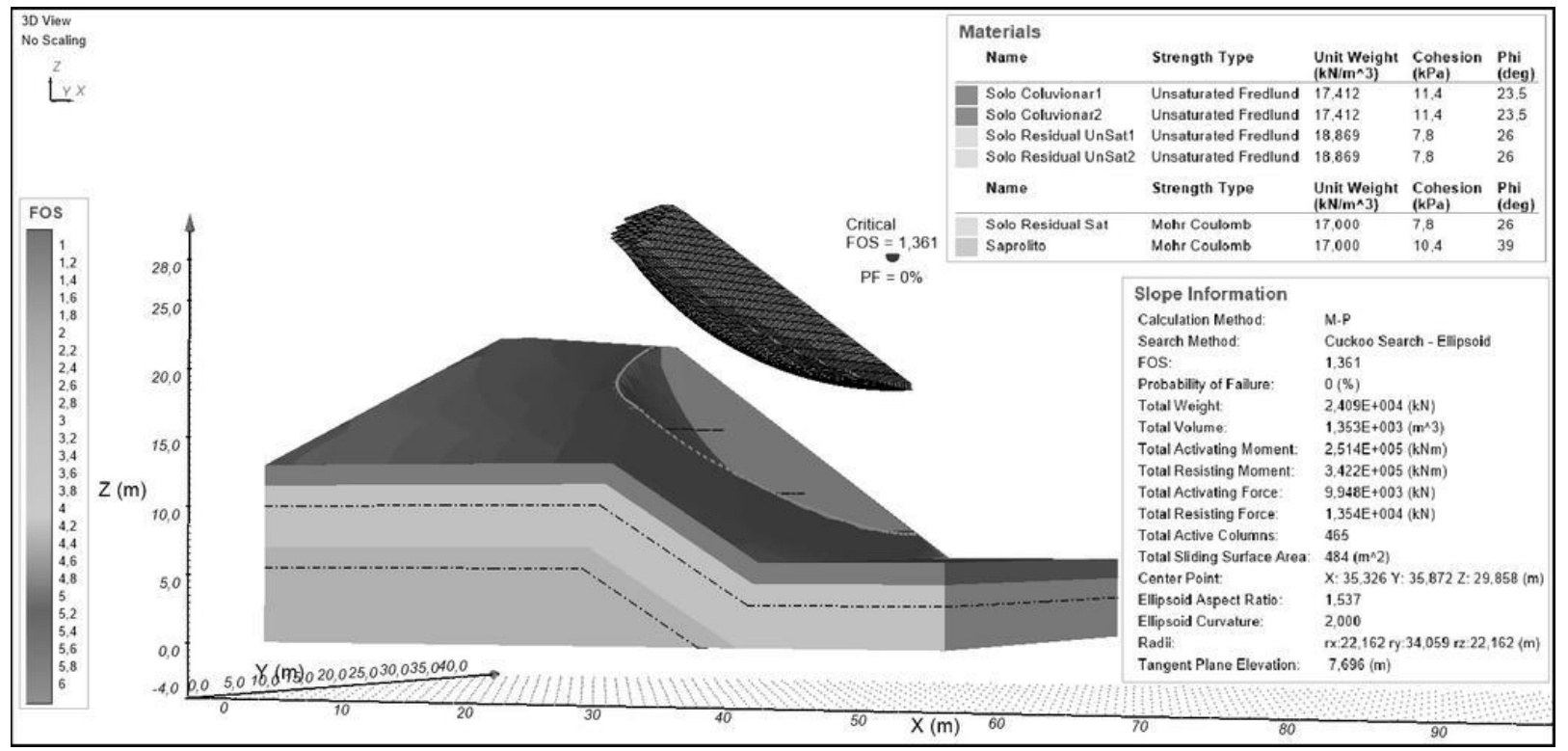

Fig. 8. 3D probabilistic analysis in SVSlope with water level at 7.5 meters. 
The safety factor (SF) also showed higher values in 3D analysis, which can be justified by the same previous reason, it is possible to analyse more possibilities of surfaces of critical rupture along the entire length of the slope. It is also possible to analyse different forms of surfaces, achieving a rupture surface more faithful to what could occur in reality, presenting, in this case in $3 \mathrm{D}$, a safer scenario.

Likewise, the mobilized mass volumes were different between $2 \mathrm{D}$ and $3 \mathrm{D}$ analyses, indicating lower values in $3 \mathrm{D}$. This is due to the $2 \mathrm{D}$ visualization estimating the volume from the area above the critical break surface of the slope and multiply by the longitudinal length, that is, this entire area along the length of the slope is considered as the mass to be displaced with the possible landslide. However, in 3D visualization it is possible to detail this volume better; not considering it continuous along the length, but more punctual, with defined edges and different depths of location of the critical rupture surface. In addition to, the modelling of the slope incorporates several cross sections and not just one.

It was observed that, the results obtained with the two water level positions, at 6.5 meters and 7.5 meters deep, were close.

In the $2 \mathrm{D}$ visualization the results were the same, that is, the change in the water level, which is located in the saprolite, did not interfere in the behaviour of the soils above, colluvial and residual soil, maintaining the same results in terms of probability of rupture, safety factor and volume of mass mobilized.

In the $3 \mathrm{D}$ visualization the change in the water level position showed little interference. The depth of 6.5 meters had greater SF, mostly, when compared to the SF of the depth of 7.5 meters, for the same suction scenario.

However, the volumes of mass mobilized, besides not showing a pattern of behaviour with the increase of the superficial suction, were varied when compared in terms of the depth of the water level. Therefore, it did not present a model of behaviour with respect to the volume, in the two results analyses.

\section{Conclusions}

The use of probabilistic analysis in the stability of the slope makes it more faithful to what happens in reality, because this analysis considers the variation of the soil shear strength parameters, unlike the deterministic analysis that considers only the average value of the parameters.

Furthermore, the probabilistic analysis provides the probability of rupture of the slope, which for this study resulted in low values, indicating an expected performance level above the average, good and high for the suction scenarios, that is, low probability of occurrence of landslide.

The incorporation of suction in unsaturated soils (colluvial soil and residual soil) interfered with the results of rupture probability and safety factor (SF). It can be concluded that the increase of suction in the superficial layer of the soil provides greater security for the slope study, because it was obtained less probabilities of rupture and, also, greater safety factors.

In reference to the volume of mass mobilized, the increase in suction did not directly interfere with this result, then no relationship can be established. The suction scenario of $20 \mathrm{kPa}$ from $2 \mathrm{D}$ analysis showed the most insecure character with $0.28 \%$ of probability of rupture (highest value) and SF of 1.248 (lowest value). In contrast, the suction scenario of $120 \mathrm{kPa}$ from 3D analysis was the most optimistic, with $0 \%$ of probability of rupture (lowest value) and SF of 1.850 for the water level at 6.5 meters and SF of 1.714 for the water level at 7.5 meters (higher values).

Through the simulations, it can be concluded that the $3 \mathrm{D}$ analysis presented a safer scenario when compared with the $2 \mathrm{D}$ analysis, with lower probability of rupture and greater safety factors. The three-dimensional modelling allows encompassing several cross sections which makes it more reliable, in addition to expanding spatially the search for the critical rupture surface, thus resulting in volumes of mobilized mass more punctual and similar to reality.

The change in position of the water level on the slope, however, showed little difference in the results, in 2D analysis it presented the same values for both positions. In the $3 \mathrm{D}$ analysis, it was noticed that the safety factors (SF), in most cases, were higher when the water level was closer to the surface. The little difference between these results is because the critical rupture surface did not reach the two imposed water levels. Furthermore, both water levels are in the saprolite, a material that presents fracturing, making it difficult for water to pass to the more superficial soils, unsaturated soils.

Finally, in view of the entire study, it is concluded that the analysed slope, located in the state of São Paulo in Brazil, in the area dominated Serra Pelada of BR 116 $\mathrm{PR} / \mathrm{SP}$, is safe regarding its global stability for rupture.

\section{Acknowledgements}

The authors would like to thank the ANTT - National Land Transport Agency, Autopista Régis Bittencourt and the Graduate Program in Civil Construction Engineering (PPGECC / UFPR).

\section{References}

1. D. M. S. Gerscovich. (2016). Slope stability. São Paulo: Oficina de Textos. 2 ed. (In Portuguese).

2. B. P. A. Tonus. (2009). Slope stability: evaluation of the limit equilibrium methods applied to a colluvial and residual slope of the mountain range of Paraná. Master in Geotechnics, Federal University of Paraná, Curitiba. (In Portuguese).

3. F. A. M. Marinho, A. Gens, A. A. Josa. (1994). Suction measure with filter paper method. X Brazilian Conference on Soil Mechanics and Foundation Engineering. vol 2, 515-522. 
4. M. M. Victorino. (2015). Influence of rain on poropressures and stability of road embankments of a stretch of BR 376 in Serra do Mar, Paraná. Master in Geotechnics, Federal University of Paraná, Curitiba. (In Portuguese).

5. N. F. Fernandes, R. F. Guimarães, R. A. T. Gomes, B. C. Vieira, D. R. Montgomery, H. Greenberg. (2001). Geomorphological constraints of landslides: evaluation of methodologies and application of a prediction model for susceptible areas. Brazilian Journal of Geomorphology. vol 2, n. 1, 51-71. (In Portuguese).

6. E. F. Batista. (2019). Methodologies for economic measurement and vulnerability assessment with application in sections of the Régis Bittencourt highway, São Paulo-SP. Master in Geotechnics, Federal University of Paraná, Curitiba. (In Portuguese).

7. M. N. B. Trevizolli. (2018). Proposed risk assessment model and landslides based on scenarios of pluviometric events: application on a slope of Serra do Mar in the PR / SP stretch. Master in Geotechnics, Federal University of Paraná, Curitiba. (In Portuguese).

8. USACE, ETL 1110-2-556. (1999). Risk-based analysis in geotechnical engineering for support of planning studies. U.S. Army Corps of Engineers Document.

9. ABNT. (2009). NBR 11682: Slope stability. Brazilian Association of Technical Standards. (In Portuguese). 